http://jmscr.igmpublication.org/home/ ISSN (e)-2347-176x ISSN (p) 2455-0450

crossref DOI: https://dx.doi.org/10.18535/jmscr/v9i2.42

\title{
Allocation of position of teeth within the dead space in complete denture prosthesis
}

\author{
Authors \\ Krati Singh $^{1}$, Jacob J Hendrick ${ }^{2 *}$ \\ ${ }^{1}$ Consultant, PT Charitable hospital, Kerala \\ ${ }^{2}$ Reader, CIIDSRC, KUHS, Kerala \\ *Corresponding Author \\ Jacob J Hendrick
}

\begin{abstract}
In order for the prosthesis to be functionally, esthetically and phonetically acceptable, it is essential that the prosthesis has adequate stability and retention and does not get displaced with the movement of muscles around it. The soft tissues surrounding the denture form the borders of the prosthesis, therefore the way the denture relates with the muscles is critical. The neutral zone is region where the forces generated by the muscles surrounding the denture are neutralized. When a denture lies in the neutral zone, it doesnot interfere with the movement of muscles during the physiologic movements. The arrangement of teeth and the contour of the denture is established by the neutral zone. In this case report, the neutral zone of the patient was recorded using the swallowing technique and the arrangement of the teeth was done accordingly.
\end{abstract}

Keywords: oromuscular forces, deadspace, ridge relations, buccal corridor.

\section{Introduction}

A clinician often comes regularly across severely resorbed mandibular residual alveolar ridges (RAR) wherein the stability of the prosthesis is bound to be compromised. The key determinant of stability of mandibular denture is the neuromuscular control and coordination of the patient, while the parameters of denture are under dentists control. The placement of teeth within a zone of neutrality between the muscular forces on either side has been considered as a significant contributor to denture stability in such cases. The impact of this zone is even on the natural teeth which are embedded within the bone. Interference by natural teeth into neutral zone results in abnormal tooth positions (crowding) which lead to hygiene maintenance issues. ${ }^{1}$ The neutral zone is also a convenient guide to develop physiologic contours for the polished surfaces of the mandibular denture and for determining physiologically appropriate facio-lingual tooth positions. Polished surfaces of the denture have to bear the brunt of the muscular forces both from outer side (buccinator) and from inner side (tongue). ${ }^{2}$ By definition, the neutral zone is a latent space between muscles on either side of the natural teeth and it is this zone where the forces are generally equal in magnitude. ${ }^{3}$ there are however certain pathological conditions where the balance may not be true as in the case of ankyloglossia or tongue tie. ${ }^{4}$ The arrangement of the teeth as governed by the neutral zone ensures that the outwardly directed forces by the tongue on the denture are counteracted and 
neutralized by the inwardly directed forces applied by the cheeks and the lips. The muscles surrounding the denture apply forces on it during normal neuromuscular functions such as phonation, mastication, deglutition and facial expressions. These forces applied may serve to stabilize the denture or dislodge it. The purpose of recording the neutral zone is to locate that area in the edentulous mouth where in these forces stabilize the prosthesis rather than dislodge it. ${ }^{5}$

Another common occurrence in complete denture rehabilitation is presence of bilateral severe undercuts within the residual alveolar ridges that impact both treatment procedures as well as the design of the prosthesis. this article presents a unique case of these two situations that were encountered in a patient. Successful management of both conditions have also been presented.

\section{Case Report}

A 63 years old male patient reported to the department of prosthodontics with the complaint of missing teeth and difficulty in mastication. The patient was completely edentulous and desired a complete denture prosthesis. Patient's medical, social, drug history were non significant whereas dental history revealed extraction of teeth few months ago. While there were no negative clinical findings extraorally, there were bilateral severe maxillary undercuts present in the maxillary edentulous foundation that demanded different treatment planning (Fig 1 A). Treatment options presented to the patient included an implant supported fixed or removable denture or a modified conventional complete denture. In order to aid in the stability of the denture, the neutral zone of the patient's oral cavity required to be recorded and the teeth placed accordingly. The polished surface of the denture was also made in accordance to the muscle contours.

The treatment started with makingmaxillary and mandibular primary impressions in stock trays using impression compound (DPI Pinnacle, Mumbai) and the impression was poured with dental plaster (Neelkanth Minechem, Rajasthan, India). The custom trays and final impression technique for the maxillary arch was made using a sectional impression technique (Fig 1 B), ${ }^{6}$ while conventional technique was done for mandibular impressions. Both custom trays were fabricated in autopolymerizing resin (Dentsply India, Gurgaon) and border moulding was done followed by making of final impression with zinc oxide eugenol impression paste (DPI Impression Paste, Mumbai). Jaw relations were recorded using modified denture bases and occlusal rims (Fig 1 C,D) that involved placing a retaining mechanism for low fusing compound impression material. Thin orthodontic wire was bent into retentive loops which were then attached to the denture base.

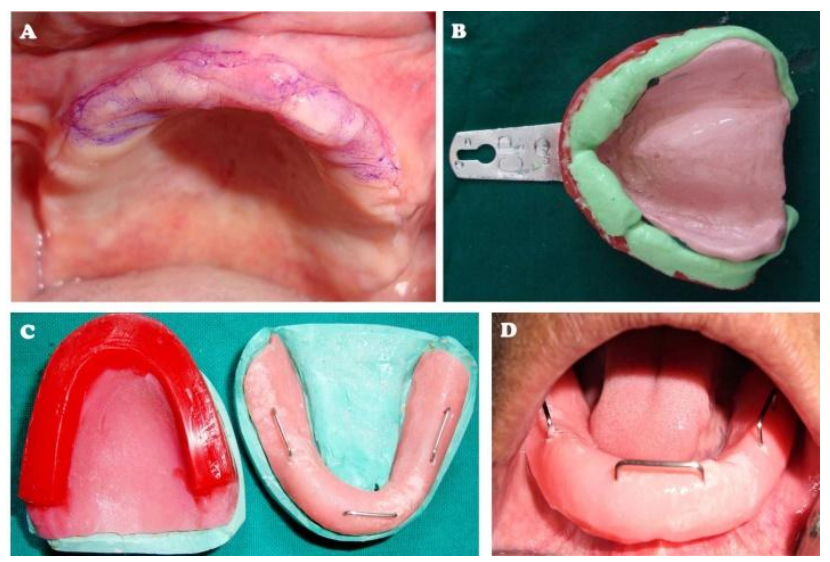

Figure 1: (A) Intra oral view of maxillary ridge showing severe bilateral undercuts (B) Sectional final impression(C) Denture base and occlusal rims with modifications (D) Modified mandibular denture base tried in patients mouth

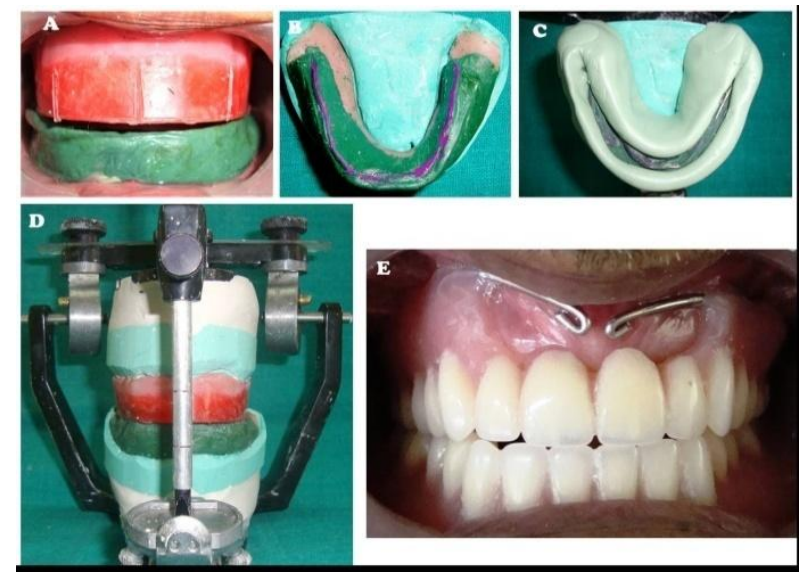

Figure 2: (A) Mandibular modified occlusal rims (B) Recorded neutral zone (C) Putty index around neutral zone(D) Mounted casts on semi adjustable articulator (E) Completed modified prosthesis 
The material used to record the neutral zone on the mandibular denture base was green stick compound (DPI) whose fusion temperature is 43.5 degrees centigrade. The material was softened in a water bath set to a temperature of $140^{\circ} \mathrm{F}$ followed by kneading and adaptation. Before recording the neutral zone, it is essential to establish a correct vertical dimension (Fig 2 A) and to deprogram the muscles responsible for mandibular posture. After the rim became sufficient soft, the mandibular denture base was placed intraorally and the patient was asked to swallow. The patient was asked to perform functional movements of the lips, cheek and tongue while material was soft. The maxillary record base is not inserted intraorally while recording the mandibular neutral zone in order to avoid compressive interferences if occlusal contacts are encountered during this functional recording procedure.Next, the record base with recorded neutral zone was seated on the cast (Fig 2 B). Putty elastomeric impression material (Aquasil, Dentsply, Germany) was used to make the neutral zone index (Fig 2 C). Now, these records were replaced accurately and securely on the casts that were mounted earlier on a semi adjustable articulator (Fig 2 D). A new mandibular record base along with wax occlusal rim was fabricated. The maxillary anterior teeth and maxillary first premolars were arranged using the conventional technique. The mandibular anterior teeth were arranged such that the mandibular teeth fall within the neutral zone, as dictated by the facial and lingual indices. The mandibular and the maxillary posterior teeth were arranged next. In preparation for external impressions used to define denture polished surface contours within the neutral zone, carefully remove all. Flasking, processing, finishing and polishing of denture was then done using conventional method. to overcome the problem of bilateral undercuts in the maxillary denture, a stainles steel orthodontic wire was adapted and placed within the labial vestibule (flangeless denture) (Fig 2 E). The patient was instructed regarding post insertion care of the prosthesis. The patient was highly satisfied with the outcome of the overall treatment.

\section{Discussion}

With gradual, irreversible resorption of the alveolar ridge, the surface area of the denture base decreases which compromises the retention and stability of the complete denture. while deficient retention can be overcome by incorporating features like gravitational pull or the weight of the denture, incorporation of features for improving stability are less investigated. This may be due to the reason that patients mostly learn how to hold their dentures sooner or later. The positioning of the teeth and contour of the flange becomes critical in such cases, since minor error in position can expose the denture to muscular forces that they may not want to mess with. The positioning of the teeth and the polished surface of the denture should be established in harmony with the musculature in order to achieve a prosthesis that is not dislodged by the musculature. The range of muscle movements should be recorded carefully and incorporated in the fabrication of the complete denture. ${ }^{8}$ Two conditions must be satisfied to make it possible for the resting muscles to fix a denture. The first has to do with the inclination of the polished surfaces of the dentures. The second concerns the position of the polished surfaces of the denture between the cheeks and the lower lip on the one side and the tongue on the other side. ${ }^{2,8}$ The complete denture prosthesis should be in harmony with the musculature in order to deliver a prosthesis that is esthetically, phonetically and functionally optimum. It is essential that the importance of the tooth position and the flange form and contour is recognized.

The neutral zone also known as the dead space, the stable zone, or the zone of minimal conflict is the zone in the oral cavity where the forces exerted by the muscles surrounding the prosthesis during function became neutralized. Sir Wilfred Fish was the first to conceptualise the neutral zone in the year 1931. ${ }^{8,}{ }^{9}$ In general, boundary conditions that define the neutral zone are developed through muscular contraction and relaxation during the various functions of mastication, phonation, deglutition, and facial expression. The techniques most commonly used for recording the neutral zone were found to be 
swallowing and phonetics. $^{10}$ However, other techniques such as sipping water, licking the lips, smiling, pursing the lips, sucking, masticating, mouth exercises (including tongue movements, blowing, protruding of the tongue, exercise movements of the lips, cheek, and tongue, facial expression, opening and closing), and whistling have also been reported. ${ }^{11,12}$ The soft tissues surrounding the complete denture exert forces on the prosthesis which may either stabilize the denture or dislodge it. The denture should be fabricated in accordance to the physiologic movement of the muscles in order to deliver a prosthesis that is stable in patient's mouth. ${ }^{13}$ Arrangement of the teeth without recording the neutral zone places the teeth in a zone where horizontal forces are applied on the prosthesis, and the prosthesis is dislodged. ${ }^{14}$ The teeth arrangement and the contour of the polished surface is thus governed by the musculature, as a result the denture will not dislodge during the speaking, mastication or swallowing. ${ }^{15}$

While the basic mechanism remains the same, different materials have been used to record the neutral zone. Among recent advances soft liner has been used as a recording material. ${ }^{16}$

However the biocompatibility of such materials is questionable since they have been shown to produce epithelial changes due to the plasticizer content. ${ }^{17}$ However, since using them for recording neutral zone is a short term procedure, they may be used to record neutral zone till better materials are available.

\section{Conclusion}

Positioning the artificial teeth in the neutral zone achieves two functions. First, the teeth will not interfere with the normal muscle function and second, the forces exerted by the musculature on the denture are more favourable for stability and retention. Therefore, recording the neutral zone is essential in order to fabricate a prosthesis that does not interfere with the movement of muscles during physiologic movement and thus stays stable intraorally.

\section{References}

1. Jain P, Rahman SU, Mattoo KA. Bansal V. Orthognathic surgery as part of pre prosthetic mouth preparation. JMSCR 2019;7(11): 777-780.

2. Rathi N, Rahman S, Mattoo KA. Creating oral musculature balance in a mandibular complete denture. International Journal of Medical Reviews and Case Reports 2020; 4 (6)

3. Glossary of prosthodontic terms- $9^{\text {th }}$ edition. J Prosthet Dent

4. Mattoo KA, Kumar A, Prajapat R. Ankyloglossia or tongue tie - Problems associated with it - A clinical report. Clinical Dentistry 2012:6: 42-45

5. Beresin VE, Schiesser FJ (1976) The neutral zone in complete dentures. J Prosthet Dent 1976:36(4):356-67.

6. Mattoo KA, Shikha. A novel impression technique for recording bilateral severe undercuts with rigid impression materials in completely edentulous patients. International Dental Journal of Students Research 2016; 4(3): 163-66

7. Rathi N, Mattoo K. Artless solution to resolve the problem of retention in resorbed alveolar ridge cases. Webmed Central Rehabilitation 2014;5(9):WMC004709

8. Fish E. Using the muscles to stabilize the full lower denture. J Am Dent Association. 1933; 20(12):2163-9. 5.

9. Fish EW. An analysis of the stabilizing force in full denture construction. Br Dent J. 1947; 83:137-42.

10. Agarwal S, Gangadhar P, Ahmed N, Bardwaj A. A Simplified Approach for Recording Neutral Zone. J Indian Prosthodont Soc 2010;10(2):102-4.

11. Cagna DR, Massad JJ, Schiesser FJ. The neutral zone revisited: from historical concepts to modern application. J Prosthet Dent 2009;1010(6):405-12. 
12. Brill N, Tryde G, Cantor R. The dynamic nature of the lower denture space.J Prosthett Dent 1965;15(3):401-18.

13. Yeh YL, Pan YH, Chen YY.Neutral zone approch to denture fabricationfor severe mandibular ridge resorption patient : a systematic review and modern literature. J Dent Studies 2013;8432-8.

14. Massad JJ, Cagna DR, Goodacre CJ, Wick RA, Ahuja SA. Application of neutral zone in prosthodontics.. Wiley Blackwell 2017.

15. Porwal A, SasakiK. Current status of the neutral zone: A literature review.J Prosthet Dent 2013;109:129-134.

16. Rathi N, Yunus N, Mattoo KA. Technique for Recording Neutral Zone with a Soft Liner. Journal of Clinical Research in Dentistry 2019;2 (2): 1-2

17. Mattoo KA, Garg R, Gupta A, Jain N. Toxicology and biocompatibility of dental materials: A review. Res J Pharmac Biol Chem Sci, Oct 2012;3(4):1091-99. 